\title{
Korean University Students' Perceptions of Teacher Motivational Strategies
}

\author{
Michael Heinz \\ Hankuk University of Foreign Studies \\ Seoul, Republic of Korea \\ Chris Kobylinski \\ Hankuk University of Foreign Studies \\ Seoul, Republic of Korea
}

\begin{abstract}
ELT (English Language Teaching) is a significant component of the Korean Education system from elementary school to university. The ELT industry is comprised of two distinct types of teachers: Native English speakers and Native Korean speakers. While both groups share similar educational goals, there is often very little interaction between the two groups. Both groups spend considerable time with students and have considerable influence on students studying English in South Korea. The goal of this research was to see what students thought of the motivational strategies employed by each group, in hopes of being able to see how both groups could learn from each other. Motivation is one of the most important elements of language learning and this research hoped to find how each group of teachers motivated students. The focal point of this research was a survey focusing on a set of motivational strategies identified by Dornyei. This survey adapted Dornyei's survey to focus on how the students perceived the strategies, rather than how teachers assessed their own motivational strategies. The survey was given to two groups, students in an undergraduate level Practical English course and to students in a graduate level interpretation and translation department to see how the students perceived the motivational strategies of each group. The survey revealed a few clear cut differences among each group. The surveys showed that Native English teachers provided instinct motivation through various tasks and by creating a positive classroom environment. Native Korean speakers excelled in creating extrinsic motivation, by providing realistic goals and by stressing the importance of English in the working world.
\end{abstract}

Keywords: ELT, South Korea, motivation, EFL, motivational strategies, Donryei 


\section{Introduction}

Given the complexity inherent in learning a foreign language, it is not surprising that motivating students has been identified as being one of the most difficult aspects of teaching ELT; outranking even the selection of teaching methodology, subject matter proficiency, and textbook and curriculum guide usage (Veenman, 1984). Indeed, a lack of motivation is often a recurrent problem in EFL classrooms (Dornyei \& Kubanyiova, 2014; Ushioda, 2013). Given its importance, this paper seeks to further research on motivational strategies and chose the South Korean context as its focal point.

The South Korean ELT industry is massive in scale with ELT-based institutions dotting the landscape in every conceivable direction. While the industry is comprised primarily of domestic, ethnically Korean English teachers for whom English is a second language, a considerable number of native English speakers from the United States, Canada, Australia, and the United Kingdom also teach in the ELT industry at all levels and age ranges. These two groups: Native Korean speaking English teachers (hereafter referred to as NKS teachers) and Native English speaking English teachers (hereafter referred to as NES teachers) have limited interactions with one another despite the common goals they pursue within the same educational environment.

The researchers themselves being NES teachers who have worked in the Korean ELT industry for over a decade became accustomed to Korean students remarking with great frequency on the differences between NKS and NES teachers. As such these anecdotal comments made by Korean students about the differences between NKS and NES teachers led the researchers to ponder a number of research questions:

1. How do the motivational strategies of NKS and NES teachers differ?

2. How do students feel about the differences between these motivational strategies?

\section{Literature Review}

There are a great many articles written about student motivation and language learning with no small number of models having been created in an attempt to understand the subject (eg., Clement, 1980; and MacIntrye, Clement \& Noels, 1998). Within the field two figures stand out as being relative authorities on motivation and second language acquisition: Robert C. Gardner and Zoltan Dornyei.

Gardner established his 'Socio-educational model' as a model for understanding motivation the 1960's and has been actively refining it ever since (Gardner \& Lambert, 1959; Gardner, 1985; Gardner \& Lalonde, 1985). His model is broadly divided into two types of motivation: instrumental and integrative motivation. Instrumental motivation relates to things such as test scores, college admissions, and job acquisition. Alternatively, integrative motivation concerns a learner's desire to embrace the target language's culture and community, which 
Gardner singles out as being a more significant determiner of motivation for students.

Additionally Gardner (2007) emphasizes the unique nature of motivation as regards the acquisition of a second language. Whereas for most scholastic subjects the educational context is a given in terms of understanding the roots of motivation, second language acquisition requires examination of the cultural context related to the second language. Common scholastic subjects are taught almost entirely within the student's native culture while language study requires the taking on of cultural traits such as pronunciation or vocabulary to successfully acquire the new language. Thus educationally relevant variables are as significant as culturally relevant variables.

On the other hand, Dornyei's model, the L2 Motivational Self System, consists of three components: the Ideal L2 self, the Ought-to L2 self, and the L2 learning experience (2009). Dornyei defines those components in the following manner: the Ideal L2 self is "the L2 specific facet of one's ideal self;" Ought-to L2 is "he attributes that one believes one ought to possess in order to avoid possible negative outcomes;" and the L2 experience is "situation-specific motives related to the immediate learning environment and experience (2009)."

Motivation in various models is seen as a quality predictor of student achievements. Dornyei asserts that, "Motivation is one of the main determinants of second/foreign language achievement (Dornyei 1994, p. 273). Gardner and Bernaus (2008) found that motivation is a significant positive predictor of language learning achievements.

While that finding has a ring of intuitiveness, other studies have found that the motivational strategies adopted by language teachers influence student motivation (Dornyei, 1994; Dornyei, 1998; Dornyei, 2001a; Dornyei, 2001b; Bravo, Intriago, Holguin, Garzon \& Arcia, 2017). Within the South Korean context, Guillautaux and Dornyei (2008) explored the connection between the language learning motivation of students and the motivational teaching practices of teachers. The motivation orientation of language teaching (MOLT), a classroom observation instrument was created to augment self-report questionnaires for the study of 40 classroom that included 27 teachers and more than 1,300 students. In the end, the study demonstrated a clear relationship between the use of teacher's motivational strategies and the language learning motivation of the students. Papi and Abdollahzadeh (2012) replicated the study carried out by Guillautaux and Dornyei and reached similar conclusions but added a need to focus more studies on motivation in tertiary settings due to the unique context of those settings.

However, it is important to note that some discrepancy can exist between the self-reporting of the motivational strategies implemented by teachers and the perspectives of students. For example, Jacques (2001) examined the motivation and preferences for teaching activities of both teachers and students. Relationships were found related to motivational characteristics and perceptions of strategy use within both the teacher and the student sample. Yet, the study found that teachers had a tendency to rate activities more highly than the students did. 
More significantly, a study by Bernaus and Gardner (2008) examined more acutely the possible discrepancy between teachers' reported use of motivational strategies and students' perceived use of motivational strategies. Within the Catalan Autonomous Community of Spain, 31 English teachers and nearly 700 of their students were selected for the study. The study adapted Gardner and MacIntyre's mini-AMTB (Attitude/Motivation Test Battery) (1993) to explore the attitudes of all the participants in addition to a 26 question survey about motivational strategy use. The study concluded that motivational strategies are solid predictors of language achievement but only when reported by students, not when reported by teachers (2008).

It was the above findings that led us to examine student perceptions of motivational strategies as employed by teachers in South Korea. The present study felt that it was more significant to determine how students perceived their instructors to provide more valuable feedback than instructor self-reflection.

\section{Subjects}

\section{Graduate School Subjects}

There were 49 participants from a graduate school of interpretation and translation with highly selective admissions standards. Students admitted to that program must pass two admissions tests. The first test judges the students' writing and translation ability with an eye towards their bilingual competency. The second round of the test is an oral interview in which students are asked to perform without preparation or notes generalized interpretative processes from Korean to English and from English to Korean. The program does not rely upon any forms of standardized testing to determine who is accepted into the program. It is common for these students to have spent many years both in Korea and other western nations such as the United States. For some of these students, English is their dominant language though it is rarely their precise mother tongue as the overwhelming majority of students are of Korean ethnic descent.

\section{Undergraduate Subjects}

The undergraduate students were Korean university students from four Communicative English classes; standard credit-bearing classes for first year students. Communicative English classes are multi-skill classes designed to prepare students to study in an English speaking classroom. The students are level tested before the start of the semester and all students were placed in the highest level. Each class size ranged from 28 students to 30 students and a total of 102 participated in the survey. The level of the students ranged from fluent to upper intermediate. Most students had a good grasp of English and of academic language in their native language. The ages of the students ranged from 18 to 22 .

\section{Methodology}

For the present study undergraduate and graduate school students from the same Korean university were selected to answer a survey about the motivational strategies of NKS and NES English teachers. The undergraduate students were comprised of mostly freshman students of intermediate English 
proficiency enrolled in a required English competency course whereas the graduate school students were interpretation and translation majors possessing high level bi-lingual competency. The differences between the students' backgrounds were thought to be significant enough to produce varying attitudes between the groups and provide two different perspectives particularly in terms of exposure to NES teachers, since the graduate school were more likely to have spent more time with NES teachers both abroad and domestically based on anecdotal feedback from the student populations.

The survey was drawn up based on a survey device used by Dornyei and Cheng (2007) in a study of 387 Taiwanese English teachers that included a multitude of questions about motivational strategies and the frequency of their usage.

In the end 47 items about motivational strategies were drawn up and students were asked to rate the frequency of their usage by both NKS and NES English teachers in addition to student background questions to determine what, if any, significant differences exist between both groups (appendix). A Likert scale of 1 to 6 was utilized to avoid the possibility of neutral answers due to the large number of questions on the survey. In total there were 151 participants in the study.

\section{Findings}

The first part of the survey that contained questions about previous learning experiences provided insight into the English language learning experiences of the students. Surprisingly, there answers were quite uniform across all questions.

Both groups of students had studied English for a long period of time. The graduate school students had studied for 16.5 years on average and the undergraduate school students for 10.4 years. The graduate school students reported that they spent 6.5 years studying with NES and 9.1 years with NKS. The undergraduate students reported studying 5.1 years with NES and 7.5 years with NKS. These numbers are very consistent given the fact that the average age of the students was estimated to differ by roughly 6 years. These numbers show a fairly constant approach to English language learning in South Korea and highlighted the perceived importance of English in the Korean educational system.

In terms of years spent studying English abroad, the graduate school students spent an average of 5.4 years abroad and the undergraduate school students spent an average of 1.7 years studying English abroad. This difference wasn't unexpected, given the age difference between the students and the importance of English in their majors.

The test scores that were optionally provided also showed that both groups were successful English language learners. The graduate school students reported an average TOEIC (Test of English for International Communication) score (scores range from 10-990) of 977 and the undergraduate students reported an average of 915 . These scores were supported by the TOEFL (Test of English as 
a Foreign Language) scores (scores range from 0-120). The graduate school students averaged 110 and the undergraduate school students averaged 106. The slight difference between these two scores was unexpected but since responses were optional it is possible that a full accounting would reveal broader gaps between the groups.

The results of the surveys were analyzed and some obvious patterns and preferences emerged. One of the first and most notable trends was that the graduate school group scored both the NKS and NES teachers lower than the undergraduate students in nearly all categories with only a few exceptions where the average scoring for a couple items was almost identical. On average they scored everything 0.6 lower. Although speculations could be made to explain this difference, the quantitative and qualitative data from the survey didn't explain this difference.

Another clear pattern was that NES scored higher on average than NKS. The NES average score was 4.1 compared to an average score of 3.5 for the NKS. These numbers are not an indicator of preference or educational quality, rather they highlight some key differences in the motivational styles of NKS and NES. The purpose of this study wasn't to show which type of teacher was preferred, rather it was to find motivational strategies and techniques that worked. The numbers as a whole show little more than an interesting pattern, however, when examined more closely, they also reveal that there are some things that NES may be able to learn from the motivational strategies of NKS and vice versa.

One of the clear differences that came out was that the students reported that NES used various activities and projects to facilitate a communicative and cooperative environment. On the statement, "Create opportunities so that students can mix and get to know each other better," NES scored 2.2 higher than NKS. This was the biggest reported difference. This is supported by another statement "Encourage student participation by assigning group activities that require involvement from each participant." NES scored 1.6 higher than NKS on this statement.

In terms of classroom environment, statements 1, 15, 30, and 43 again showed a higher average score for NES. NES scored 2 full points higher on statement 1, "Bring in and encourage humor and laughter frequently in your class." NES scored 1.3 higher on statement 15, "Make sure that grades reflect not only the students' achievement but also the effort they have put into the task;" 1.4 higher on statement 30 , "Create a supportive and pleasant classroom climate where students are free from embarrassment and ridicule;" and 1.5 higher on statement 43, "Encourage students to share personal experiences and thoughts as a part of the learning tasks."

The survey also showed a higher average score for NES in terms of lesson content and format. Students felt that NES were better able to delve into the cultural aspects of English. For the statements which said, "...familiarize the learners with the cultural background of the English language," NES scored 1.8 higher. Statement 12, “...introduce in their lessons various types of interesting content and topics which students are likely to find interesting," NES scored 1.3 higher. 
Another important difference was that the students felt that NES did a better job of communicating the importance of communicative competence, while NKS were more focused on grammar. For the statement that said, "Make it clear to students that the important thing in learning a foreign language is to communicate effectively rather than worrying about grammar mistakes," NES scored 1.8. While this may seem like an obvious advantage, the qualitative feedback showed that a strong focus on grammar was also valued by the students, as they felt it better prepared them for standardized testing.

One area where NKS scored better was in terms of practical motivation. While NES scored better on statements that related to integrative motivation, NKS scored higher on statements related to instrumental motivation. NKS's emphasis on stressing the importance of English for their lives and career was reflected in statement 9, "Regularly remind students that the successful mastery of English is beneficial to their future." NKS scored .9 higher on this statement.

In addition to scoring higher on items concerned with instrumental motivation, NKS also scored higher on items related to promoting realistic goals for students. NKS scored .5 higher on statement 10, "Encourage students to select specific, realistic and short term learning goals for themselves." In addition to helping students select short term goals, this also shows an emphasis on giving the students responsibility, as the goals were selected by the students themselves and not prescribed by the teacher.

Overall, the quantitative data revealed many patterns. NES scored better on segments that related to integrative motivation. Students felt like the classroom environment, cultural aspects, content, and the format of the classes showed stronger signs of effective motivational strategies for NES. On the other hand, NKS scored better on statements related to instrumental motivation and practical goal setting.

\section{Analysis and Conclusions}

After the survey results had been collected and partially analyzed, a group of students from both the undergraduate group and the graduate school group were interviewed to aid in the interpretation of the data. The students were asked to describe the differences between NKS and NES English teachers in terms of motivational strategy and assess the strengths of both groups.

The undergraduate students viewed NES as more likely to utilize group work and various types of content such as video clips and language content that is practical in nature. Additionally they indicated that they feel that NES maintain a more relaxed atmosphere in the classroom than their NKS counterparts. While they were positive about the atmosphere created by NES, they felt that the atmosphere created by NKS was more structured and utilized clearer forms of assessment.

The graduate school students expressed similar opinions about the contrasting motivational strategies of both groups. Overall the graduate school students felt that NES were more engaging, encouraging, accepting of mistakes, and enthusiastic. Students felt that NES stressed positive feedback, flexibility, and a desire to move towards acclimation within an English speaking 
environment. Students stressed that in Korea, most NES did not have to follow a set curriculum and utilized discussions and essay writing more than NKS.

The graduate school students had seemingly negative things to say about NKS but were convinced of the results of such methods. NKS were characterized as being patient but not providing verbal encouragement; being less flexible; not being passionate; not using English often in the classroom; and relying on "threats" to motivate students, a strategy they said was common across all subjects in Korean schools. While these attributes have a ring of negativity to them, the graduate school students felt that they were necessary to ensure high test scores on standardized tests, to keep a fast pace within the classroom, and to accommodate students that are shy or reticent about discussing topics in a classroom environment.

\section{Limitations}

One of the limitations of this study was its lack of specificity. Students were asked to generalize quite broadly about years of experience with a variety of teachers which amounts to a considerable amount of over-generalization. Still the research questions were created based in part on student tendencies to make such generalizations in their remarks about classroom environments. Being able to examine a group with more homogenous backgrounds could produce interesting results.

Another limitation of this study was its implementation by native English speakers to Korean students. As a result of their knowledge that we would be reviewing the data it may have skewed opinions even at a subtle level to try to appease the researchers in some fashion. Utilizing a third party in future studies may be a reasonable remedy for this situation.

Perhaps more significantly, the lack of random sampling to create the data means the results are only valid for this group of students. In future studies random sampling should be utilized to generate results with greater validity. In terms of internal validity items 3 and 34 were selected to measure internal consistency and the coefficient generated was 0.599 which suggests a modest correlation between two similar items. It should be noted that those items are not identical as item 3 is about creating opportunities for students to interact through group work whereas item 34 is about "requiring" students to work in groups to improve cooperation. However these were the two items with the closest relationship to one another.

One of the conclusions of this survey is that different goals drive the usage of differing motivational strategies but it would be interesting to see how teacher training for both groups generally differs. Also it would be interesting to look at how the goals for NES and NKS are formulated or promulgated. Do NES tend to concern themselves less with standardized tests because they are given specific directives by administrators or does their perspective arise from their cultural values?

Further studies could explore the reasons for the use of different strategies and whether or not these strategies are effective for their respective goals as suggested by some students. Does a highly instrumental motivational 
strategy result in higher scores on standardized tests? If so, many such strategies could be of use to NES tasked with teaching Korean students and could account for possible issues of low student satisfaction with English courses conducted by NES.

\section{References}

Bernaus, M., and Gardner, R.C. (2008) Teacher motivation strategies, student perceptions, student motivation, and English achievement. The Modern Language Journal, 92, 387-402. doi: https://doi.org/10.1111/j.1540-4781.2008.00753.x

Bravo, Jorge Cevallos, Eder A. Intriago, Jhonny Villafuerte Holguin, Gustavo Molina Garzon, Luis Ortega Arcia (2017). Motivation and Autonomy in Learning English as Foreign Language: A Case Study of Ecuadorian College Students. English Language Teaching, Vol. 10, No. 2, 100-113. doi: https://doi.org/10.5539/elt.v10n2p100

Cheng,H. F., \& Dörnyei, Z. (2007). The use of motivational strategies in language instruction: The case of EFL teaching in Taiwan, Innovation in language learning and teaching, 1, 153-174. doi: https://doi.org/10.2167/illt048.0

Clément, R. (1980). "Ethnicity, contact and communicative competence in a second language". In H. Giles, W. P. Robinson \& P. M. Smith (Eds.) Language: Social psychological perspectives: Selected papers from the First International Conference on Social Psychology and Language held at the University of Bristol, England, July 1979. Oxford: Pergamon.

Dornyei, Z. (1994). Motivation and motivating in the foreign language classroom. The Modern Language Journal, 78, iii, 273-284. doi: https://doi.org/10.1111/i.1540-4781.1994.tb02042.x

Dörnyei, Z. (1998). Motivation in second and foreign language learning. Language Teaching, 31(3), 117-135. doi: http://dx.doi.org/10.1017/S026144480001315X

Dörnyei, Z. (2001a). Motivational Strategies in the Language Classroom. Cambridge: Cambridge University Press. doi: https://doi.org/10.1017/cbo9780511667343

Dörnyei, Z. (2001b). Teaching and Researching Motivation. Harlow: Pearson Education Limited. doi: https://doi.org/10.2307/3588444

Dörnyei, Z. (2009). The L2 motivational self system. In Z. Dörnyei, \& E. Ushioda (Eds.),

Motivation, language identity and the L2 self (pp. 9-42). Clevedon, England: Multilingual Matters.

Dornyei, Z., \& Kubanyiova, m. (2014). Motivating learners, motivating teachers: Building vision in the language classroom. Cambridge: Cambridge University Press. doi: https://doi.org/10.14746/ssllt.2013.3.3.7

Gardner, R. C., \& Lambert, W. E. (1959). Motivational variables in second-language acquisition. Canadian Journal of Psychology, 13(4), 266-272. doi: http://dx.doi.org/10.1037/h0083787

Gardner, R. C., \& Lalonde, R. N. (1985). Second language acquisition: A social psychological perspective. Paper presented at the annual convention of the American psychological association, California.

Gardner, R. C. (1985). Social Psychology and Second Language learning: The Role of Attitudes and Motivation. London: Edward Arnold. doi: https://doi.org/10.1017/s0272263100007634 
Gardner, R. C. \& MacIntyre, P. D. (1993). “On the measurement of affective variables in second language learning". Language Learning, 43: 157-194.

doi: https://doi.org/10.1111/j.1467-1770.1992.tb00714.x

Gardner, R. C. (2007). "Motivation and second language acquisition". Porta Linguarum, 8: 920 .

Guillauteaux, M. J. \& Dörnyei, Z. (2008). “Motivating Language Learners: A Classroom Oriented Investigation of the Effects of Motivational Strategies on Student Motivation". Tesol Quarterly, 42, (1): 55-77. doi: https://doi.org/10.1002/j.1545-7249.2008.tb00207.x

Jacques, S. R. (2001). "Preferences for instructional activities and motivation: A comparison of student and teacher perspectives". In Z. Dörnyei \& R. Schmidt (Eds.), Motivation and second language acquisition. Honolulu: University of Hawaii Second Language Teaching and Curriculum Center. doi: https://doi.org/10.2307/3588443

MacIntyre, P. D., Clément, R. \& Noels, K. (1998). “Conceptualizing willingness to communicate in a L2: A situational model of L2 confidence and affiliation". The Modern Language Journal, 82: 545-562. doi: https://doi.org/10.1111/j.1540-4781.1998.tb05543.x

Papi, m., \& Abdollahzadeh, E. (2012). L2 teacher motivational practice, student motivation and possible L2 selves: An examination in the Iranian EFL context. Language Learning, 62(2), 571-594. doi: https://doi.org/10.1111/j.1467-9922.2011.00632.x

Ushioda, E. (2013). Motivation and ELT: Global issues and local concerns. In E. Ushioda, (Ed.), International perspectives on motivation: Language learning and professional challenges (pp. 1-17). London: Palgrave Macmillan. doi: https://doi.org/10.1057/9781137000873_1

Veenman, Simon (1984) "Perceived Problems of Beginning Teachers." Review of Educational Research Vol. 54, No. 2 (Summer), 143-178. doi: https://doi.org/10.3102/00346543054002143

\section{Appendix 1}

For the following questions please rate domestic Korean English teachers (referred to as Korean English Teachers and Native English speaking English Teachers (referred to as Native English Teachers) based on their use of motivational strategies using the following scale:

$$
\begin{aligned}
& 1=\text { Hardly Ever } \\
& 6=\text { Very Often }
\end{aligned}
$$

Use your general impression as a guide as opposed to thinking just about one teacher for either category.

1. Bring in and encourage humor and laughter frequently in your class.

2. Show students that they respect, accept and care about each of them.

3. Create opportunities so that students can mix and get to know each other better (e.g. group work, game-like competition).

4. Familiarize the learners with the cultural background of the English language.

5. Explain the importance of the 'class rules' that you regard as important (e.g. let's not make fun of each other's mistakes) and how these rules enhance learning, and then ask for the students' agreement. 
6. Give clear instructions about how to carry out a task by modelling every step that students will need to do.

7. Invite senior students who are enthusiastic about learning English to talk to your class about their positive English learning experiences/successes.

8. Monitor students' accomplishments, and take time to celebrate any success or victory.

9. Regularly remind students that the successful mastery of English is beneficial to their future (e.g. getting a better job or pursuing further studies abroad).

10. Encourage students to select specific, realistic and short-term learning goals for themselves (e.g. learning 5 words every day).

11. Design tasks that are within the learners' ability so that they get to experience success regularly.

12. Introduce in your lessons various forms of interesting content and topics which students are likely to find interesting (e.g. about TV programmes, pop stars or travelling).

13. Make tasks challenging by including some activities that require students to solve problems or discover something (e.g. puzzles).

14. Teach the students self-motivating strategies (e.g. self-encouragement) so as to keep them motivated when they encounter distractions.

15. Make sure grades reflect not only the students' achievement but also the effort they have put into in the task.

16. Ask learners to think of any classroom rules that they would like to recommend because they think those will be useful for their learning.

17. Show your enthusiasm for teaching English by being committed and motivating yourself.

18. Break the routine of the lessons by varying presentation format (e.g. a grammar task can be followed by one focusing on pronunciation; a whole-class lecture can be followed by group work).

19. Invite some English-speaking foreigners as guest speakers to the class.

20. Help the students develop realistic beliefs about their learning (e.g. explain to them realistically the amount of time needed for making real progress in English).

21. Use short and interesting opening activities to start each class (e.g. fun games).

22. Involve students as much as possible in designing and running the language course (e.g. provide them with opportunities to select the textbooks; make real choices about the activities and topics they are going to cover; decide whom they would like to work with).

23. Establish a good relationship with your students.

24. Encourage student participation by assigning activities that require active involvement from each participant (e.g. group presentation or peer teaching). 
25. Give good reasons to students as to why a particular activity is meaningful or important.

26. Try and find out about your students' needs, goals and interests, and then build these into your curriculum as much as possible.

27. Allow students to create products that they can display or perform (e.g. a poster, an information brochure or a radio program).

28. Encourage learners to try harder by making it clear that you believe that they can do the tasks.

29. Give students choices in deciding how and when they will be assessed/evaluated.

30. Create a supportive and pleasant classroom climate where students are free from embarrassment and ridicule.

31. Bring various authentic cultural products (e.g. magazines, newspapers or song lyrics) to class as supplementary materials.

32. Make clear to students that the important thing in learning a foreign language is to communicate meaning effectively rather than worrying about grammar mistakes.

33. Notice students' contributions and progress, and provide them with positive feedback.

34. Include activities that require students to work in groups towards the same goal (e.g. plan a drama performance) in order to promote cooperation.

35. Teach students various learning techniques that will make their learning easier and more effective.

36. Adopt the role of a 'facilitator' (i.e. their role would be to help and lead students to think and learn in their own way, instead of solely giving knowledge to them).

37. Highlight the usefulness of English and encourage your students to use their English outside the classroom (e.g. internet chat room or English speaking pen-friends).

38. Motivate your students by increasing the amount of English they use in class.

39. Share with students that they value English learning as a meaningful experience that produces satisfaction and which enriches your life.

40. Avoid 'social comparison' amongst your students (i.e. comparing them to each other for example when listing their grades in public).

41. Encourage learners to see that the main reason for most failure is that they did not make sufficient effort rather than their poor abilities.

42. Make tasks attractive by including novel or fantasy elements so as to raise the learners' curiosity.

43. Encourage students to share personal experiences and thoughts as a part of the learning tasks. 
44. Enrich the channel of communication by presenting various auditory and visual aids such as pictures, tapes and films.

45. Show students that their effort and achievement are being recognized by the teacher.

46. The teacher tries to be herself/himself in front of students without putting on an artificial 'mask', and shares with them his/her hobbies, likes and dislikes.

47. Give students opportunities to assess themselves (e.g. give themselves marks according to their overall performance). 